\title{
INQUIETANTES TRASLADOS: UMA LEITURA PSICANALÍTICA DO FILME ENCONTROS E DESENCONTROS'
}

\author{
Mauricio Rodrigues Souza*
}

\begin{abstract}
RESUMO. Na busca por articulações entre psicanálise e práticas culturais - aqui representadas pela magia do cinema o presente trabalho propõe uma releitura do filme Encontros e Desencontros, utilizando-o como interlocutor privilegiado para uma discussão acerca do trato com a alteridade. Mais especificamente, direcionaremos nosso olhar para a possibilidade, presente tanto na clínica analítica quanto no filme em questão, do encontro com o inominável de si mesmo por intermédio de um estrangeiro. Trata-se de um entrechoque dialético entre o estranho mais íntimo e o íntimo mais estranho, este último vinculado ao processo primário, à lógica do inconsciente. Diante disto, aposta-se aqui que, muito embora esta não familiaridade em geral apareça vinculada a uma desconfortável angústia, possamos vislumbrar para ela uma outra expressão: aquela de potência construtiva rumo à abertura de sentido.
\end{abstract}

Palavras-chave: Psicanálise; cinema; alteridade.

\section{UNCANNY TRANSITIONS: AN ANALYSIS OF THE MOVIE LOST IN TRANSLATION}

\begin{abstract}
In search of articulations between psychoanalysis and cultural practices - here represented by the magic of cinema - this work proposes an analysis of the movie Lost in Translation, taking it as a privileged interlocutor to a discussion about otherness. More specifically, we will focus on the possibility, present both in analytical clinics and in the movie mentioned above, of an encounter with the unspeakable of the self by the means of a stranger. It's a dialectical clash between the most intimate stranger and the strangest intimate, bounded to the primary process, to the logics of the Unconscious. Therefore, we suggest that although this non-familiarity is in general associated to an uncomfortable anguish, it is possible to consider another expression to it: that one of constructive potency towards an expansion of meaning
\end{abstract}

Key words: Psychoanalysis; cinema; otherness.

\section{OMINOSOS TRASLADOS: UNA LECTURA PSICOANALÍTICA DE LA PELÍCULA ENCUENTROS Y DESENCUENTROS}

\begin{abstract}
RESUMEN. En una busca por articulaciones entre psicoanálisis y prácticas culturales - acá representadas por la magia del cine - lo presente artículo propone una relectura de la película Encuentros y Desencuentros, la cual será utilizada como interlocutora privilegiada para una discusión acerca del trato con la alteridad. De manera más específica, direccionaremos nuestra atención en la posibilidad, presente tanto en la clínica analítica cuanto en la película en cuestión, del encuentro con lo innominable de si por intermedio de un extraño. En verdad se trata de un entrechoque dialectico entre lo extraño más intimo y lo intimo más extraño, vinculado al proceso primario, a la lógica del Inconsciente. Con eso creemos aquí que, mismo que tal ausencia de familiaridad en general apareja vinculada a una incómoda angustia, podemos vislumbrar para ella una otra expresión: la de potencia constructiva direccionada a la apertura de sentido.
\end{abstract}

Palabras-clave: Psicoanálisis; cine; alteridad.

\footnotetext{
Uma versão preliminar do presente trabalho foi apresentada originalmente no GT Psicanálise, Subjetivação e Cultura Contemporânea, vinculado ao XIV Simpósio da Associação Nacional de Pesquisa e Pós-Graduação em Psicologia - ANPEPP, realizado na cidade de Belo Horizonte em junho de 2012. Segue um agradecimento aos participantes do referido grupo pelos comentários e sugestões e também à colega Berenice Blanes, do Instituto Sedes Sapientiae, pelo seu precioso e generoso apoio quando o que agora aparece em sua forma escrita era ainda apenas um esboço.

Pós-doutorado em Teoria Psicanalítica pela Universidade Federal do Rio de Janeiro. Doutor em Psicologia pela Universidade de São Paulo. Professor da Faculdade de Psicologia da Universidade Federal do Pará, Brasil. Coordenador do Grupo Filosofia, Psicanálise e Cultura, vinculado ao Diretório de Grupos de Pesquisa do CNPq.
} 
A Psicanálise e o cinema são frutos de um mesmo momento histórico, marcado pelas promessas, mas também pelas demandas sociais de um significativo avanço industrial e capitalista. De imediato, isto já remete a um interessante diálogo entre aquela e este. Com efeito, vale lembrar que a virada do século XIX para o XX nos trouxe tanto os primeiros escritos de Freud e Breuer acerca da histeria quanto a fabulosa projeção de imagens dos irmãos Lumière.

É bem verdade que a reação do hoje ilustre médico de Viena diante dos jogos de luz e sombra que apareciam nas telas da época não foi das melhores. Talvez pelo fato de Freud, apesar de descortinar em sua clínica os dramas e conseqüências do falso moralismo burguês de seu tempo, representar, sob variados aspectos, o ideal conservador desta mesma classe, marcado por uma rígida separação entre o classicismo da cultura erudita e o feitio supostamente mais melodramático da chamada cultura das massas; ou talvez, conforme sugere Rivera (2008), simplesmente por associar o cinema a uma reprovável: “... mistificação, a 'suave narcose' que, no fim dos anos 1920, irá caracterizar como função da arte” (p. $10)$.

De qualquer forma, a despeito da desconfiança de Freud, fato é que desde então acumulamos uma série de aproximações mais ou menos bem-sucedidas de ambos os lados. Estas envolveram tanto a apropriação e popularização, por parte de Hollywood, de importantes - ainda que constantemente deslocados elementos da teoria freudiana (como, por exemplo, o valor do Édipo e os conflitos relativos aos chamados "romances familiares") quanto a crescente utilização, por parte de psicanalistas e/ou professores universitários, de filmes e documentários de variados tipos como interlocutores privilegiados para debates acerca das sempre renovadas imbricações entre inconsciente e cultura. Isto não nos deve causar espanto, afinal: “... os seres humanos sempre criaram encenações ou artefatos simbólicos que, tal como os sonhos, funcionam como mecanismos de descarga das tensões, pressões, temores e desejos de todo e qualquer contexto ambiental ou social em que eles se encontrem" (Kaplan, 2000, p. 139).

Assim, é essa ao mesmo tempo espantosa e necessária capacidade de criação de uma realidade alucinatória que aproxima o sonho e a projeção cinematográfica não somente das sombras da caverna de Platão, mas também da Psicanálise. Nestes termos, ambos encontram acolhimento precisamente no seu quê de trágico e irracional, ou melhor, no tipo de racionalidade que lhes é peculiar e que, impregnada pelo desejo, permite-lhes distorções, cortes, sobreposições e reorganizações de ângulos e imagens.
Pois bem, o presente artigo se vincula a este já tradicional histórico de aproximações entre psicanálise e cinema ao propor uma releitura do filme Encontros $e$ Desencontros, escrito e dirigido por Sofia Coppola e lançado no ano de 2003. Nosso foco recairá sobre os sabores e dissabores do trato com a alteridade. Mais especificamente, direcionaremos nosso olhar para a possibilidade, presente tanto na clínica analítica quanto no filme em questão, do encontro do indivíduo com o inominável de si mesmo por intermédio de um estrangeiro. Como veremos, trata-se de um entrechoque dialético entre o estranho mais íntimo e o íntimo mais estranho, este último vinculado ao processo primário, à lógica do inconsciente.

Diante disso, apostamos aqui que, muito embora esta não familiaridade em geral apareça vinculada a uma desconfortável angústia, podemos vislumbrar para uma expressão mais criativa. Assim, como sugere o jogo de palavras presente no título original do filme de Sofia Coppola (Lost in Translation), a tradução pode e deve ser compreendida como traslado ou demanda de significado, ao invés da qualidade estática de um algo já existente a ser meramente decifrado. É o que debateremos nas próximas páginas.

Para tanto, iniciemos por alguns comentários acerca da alteridade em psicanálise, privilegiando, entre outros, um escrito em particular. Trata-se de $O$ Inquietante (Freud, 1919/1976), o qual, também traduzido como "O Estranho" ou "O Sinistro", revelase importante por nos apresentar uma ética bastante peculiar à psicanálise: aquela que ao debater a alteridade não aborda exatamente um estrangeiro, mas detecta a estranheza do inconsciente enquanto inominável de nós mesmos.

\section{ACERCA DE “O INQUIETANTE” (DAS UNHEIMLICHE)}

Originalmente publicado por Freud em 1919, na quinta edição da revista Imago, $O$ Inquietante detém pelo menos uma característica que o individualiza sobremaneira. Como bem lembra Cesarotto (1996), trata-se do texto que funciona como "dobradiça" entre as chamadas primeira e segunda tópicas freudianas. Neste sentido - vale lembrar - há aqui reformulações teóricas ocorridas em dois planos: o tópico $e$ o econômico. Em relação ao primeiro (organização do aparelho psíquico em "instâncias"), a grande mudança se fez, pois, enquanto a primeira tópica privilegiava a economia libidinal, a segunda aparece voltada para o confronto da libido com as demandas de renúncia impostas pela cultura; em outras palavras, foi incluído entre as "instâncias" psíquicas o conceito de superego. 
Quanto ao plano econômico (jogo das cargas energéticas do funcionamento psíquico), Freud havia proposto inicialmente a dominância do princípio de prazer, o qual postulava que todo organismo visaria alcançar um grau estável de tensão mínima. No entanto, o acúmulo da sua experiência clínica logo o levaria a refutar tal hipótese, acrescentando às suas ideias iniciais o que denominou de compulsão à repetição - ou seja, uma tendência do psiquismo à reprodução de experiências desagradáveis e inviabilizadoras de satisfação (Freud, 1920/1976). Isto possibilitou uma reorientação da teoria psicanalítica, agora equilibrada na força de dois conceitos específicos: Eros e Tanatos, responsáveis, respectivamente, pelas pulsões de vida e morte.

Segundo Figueiredo (1999), porém, esse novo posicionamento não teria representado uma completa refutação dos escritos anteriores de Freud, mas somente uma espécie de mudança de rumo. Assim, para este autor, o problema das leituras "canônicas" de Além do Princípio de Prazer residiria na sua ênfase exagerada e simplificadora quanto a um dualismo pulsional de natureza estática. Tal postura exclusivista reduziria a alteridade do próprio texto, aproximandose ainda de uma espécie de metafísica. Com isto - a despeito, talvez, da própria intenção de Freud (1920/1976) - seria possível perceber uma lógica da suplementaridade no que se refere aos polos compostos por Eros e Tanatos.

Nesse mesmo sentido, torna-se interessante mencionar aqui trabalhos como os de Kofman (1973) e Chnaiderman (1997), os quais, convidando-nos a um retorno a $O$ Inquietante, apontam a ocorrência desta ação complementar entre as pulsões de vida e morte no próprio texto freudiano: em primeiro lugar, pela sua estrutura fragmentada, marcada simultaneamente pelo desejo de unidade e pela necessidade da introdução de variadas rupturas e distinções; em segundo, pela conjunção de temas aparentemente tão díspares, como a estética e a angústia, a beleza e o terror. Conforme Chnaiderman (1997):

\section{É interessante observar que o texto que prenuncia a última elaboração freudiana da teoria das pulsões tenha como horizonte o sentimento estético, unindo a questão do belo à indagação sobre a morte. $\mathrm{O}$ que seria $\mathrm{o}$ sentimento "negativo" fornece prazer, um prazer do além do princípio do prazer. Eros e pulsão de morte passam a se implicar (p. 219; grifo do autor).}

Uma vez expostos em linhas gerais o lugar metapsicológico de $O$ Inquietante e o contexto histórico da sua publicação, passemos agora a alguns comentários acerca do texto freudiano em si, utilizando-o como um precioso material para reflexão acerca do tipo de alteridade de que nos fala a Psicanálise: aquela própria ao inconsciente. Sem mais preâmbulos, mãos à obra.

\section{REFLEXÕES A PARTIR DO DAS UNHEIMLICHE FREUDIANO}

Como vimos anteriormente, $O$ Inquietante (Freud, 1919/1976) representa um importante momento de transição na metapsicologia freudiana. Isto porque precede a reorientação teórica da psicanálise rumo a uma nova teoria das pulsões, agora balizada no postulado de que a vida psíquica seria regida por dois princípios simultaneamente antitéticos e complementares: Eros e Thanatos (as pulsões de vida e morte). Curiosamente, todo este movimento é feito a partir de um privilégio concedido pelo texto em questão aos domínios da estética - particularmente a literária.

Assim é que encontramos Freud (1919/1976) às voltas com aquela capacidade de a obra de arte de causar em nós a sensação de uma desconfortável inquietude (Das Unheimliche), experiência que diz respeito àquilo que seduz e, ao mesmo tempo, aterroriza $^{2}$. O que, porém, de mais específico caracteriza a abordagem freudiana de tal fenômeno do sinistro é o fato de remeter o leitor a uma dimensão última, permeada pela familiaridade. Desta maneira, há aqui a afirmação de que, sob o aparentemente incompreensível e/ou atemorizante, esconde-se algo originalmente muito próximo, ainda que afastado da

\footnotetext{
Nesse sentido, contrastando a aproximação freudiana do fenômeno do inquietante com aquela outra, própria aos especialistas em estética da época, Kofman (1973) destaca como o trabalho de Freud (1919/1976) provaria que aqueles últimos se manteriam prisioneiros de pré-conceitos metafísicos que os conduziriam a uma oposição radical entre os terrenos do belo e do feio, da atração e da repulsa, privilegiando os primeiros em relação aos segundos. Ainda para Kofman (1973), tal recusa e esse sintomático privilégio teriam servido como motivação para que Freud (1919/1976) demonstrasse como a Psicanálise teria algo a dizer sobre o tema da estética, associando-a a um caso particular de retorno do reprimido onde ficaria subentendida uma não separação entre o inquietante e os sentimentos ditos "positivos". Assim, sugere Kofman (1973), pode ser depreendida aqui a oposta de uma relação entre o inquietante, a satisfação estética e a pulsão de morte, todos associados pela emergência de conteúdos infantis anteriormente reprimidos. Ou seja: conforme a autora, a despeito da clivagem proposta pela estética tradicional, uma importante mensagem presente no texto de Freud (1919/1976) é aquela de um estranhamento dos limites entre "positivo" e "negativo". Todo prazer seria, então, misturado, heterogêneo (mêlé).
} 
consciência. Trata-se de um estranho de nós mesmos, por assim dizer, o qual aparece expresso de maneira precisa por Kristeva (1994) nos seguintes termos:

Com a noção freudiana de inconsciente, a involução do estranho no psiquismo perde $o$ seu aspecto patológico e integra no seio da unidade presumida dos homens uma alteridade ao mesmo tempo biológica e simbólica, que se torna parte integrante do mesmo. A partir de então, o estrangeiro não é nem uma raça nem uma nação. $\mathrm{O}$ estrangeiro não é magnificado como Volksgeist secreto, nem banido como perturbador da urbanidade racionalista. Inquietante, o estranho está em nós: somos nós próprios estrangeiros - somos divididos (p. 190).

Pois bem, Freud (1919/1976) propõe duas vias para o estudo de tal sensação de desassossego despertada pela criação artística. A primeira delas, de cunho etimológico, aparece voltada ao desenvolvimento desta palavra no contexto de variadas culturas; já a segunda, procurará elucidar uma essência do "sinistro" a partir da reunião de características particulares de coisas, pessoas e vivências capazes de despertar em nós tal impressão.

Ao dar início à primeira das abordagens que propôs para o estudo do inquietante, Freud (1919/1976) nos remete à análise das diferentes expressões deste sentimento em variados idiomas, como o alemão, o latim, o grego, o inglês, o francês e o espanhol. Tal esforço acabaria por revelar que, dentre os variados matizes da palavra heimlich, pelo menos um em específico coincidiria com o seu oposto imediato - unheimlich. Eis o que conduz o autor à afirmação de uma constante presença do inominável na sombra do aparentemente conhecido.

Uma vez concluída essa pesquisa de ordem filológica, Freud (1919/1976) alcança a segunda parte do seu trabalho, descrevendo e comentando variadas experiências particularmente ligadas ao sentimento inquietante. Eis quando retorna ao universo das obras de arte - particularmente da literatura -, já que adota como exemplo privilegiado da sua análise o conto $O$ Homem da Areia, do escritor alemão E.T.A Hoffmann, famoso por um estilo narrativo bastante peculiar, que remetia o leitor ao universo do fantástico e/ou sobrenatural (Hoffmann, 1817/1993). Freud (1919/1976) utiliza o conto em questão para destacar que a experiência do inquietante nos remete a uma série de elementos, como o susto e a perda de sentido e realidade (suspensão do juízo da existência). Trata-se de emoções relativas ao desamparo infantil, as quais não se ligariam a nenhuma significação, daí o surgimento da angústia enquanto representante pulsional afetivo indeterminado.

Estritamente associada a esses aspectos temos a essência da interpretação freudiana de "O Homem da Areia", a qual privilegia o conceito psicanalítico de Complexo de Castração ${ }^{3}$. Neste contexto, em termos edipianos, tal entidade sobrenatural apareceria como uma reedição da figura paterna que, estrangeira por excelência, ao se interpor em meio à ilusão de completude que inicialmente caracterizaria a relação mãe-bebê, imprimiria no psiquismo infantil a ambivalência de sentimentos como amor, ódio e temor.

Após se ocupar de O Homem da Areia, Freud (1919/1976) busca testar a plausibilidade da associação entre o sentimento do sinistro e um fator de ordem infantil pela possibilidade ou não de aplicá-la a outros contextos. Assim, remete-se a Os Elixires do Diabo, também uma novela de E.T.A. Hoffmann, para destacar a temática do "duplo", ou seja, a ocorrência de uma grande semelhança entre os personagens em termos de conhecimentos e experiências comuns. Enfim, uma confusão de identidades pautada pela mútua identificação entre os sujeitos da trama, aliada à duplicação, divisão e intercâmbio do eu (Hoffmann, 1816/1983).

É assim que somos remetidos a situações que, embora vinculadas ao cotidiano, acabariam por extrapolar este contexto, tornando-se inusitadas ou sinistras por se aproximarem de certos estados oníricos nos quais se estabeleceria uma confusão entre realidade psíquica e realidade material. Como exemplo, Freud (1919/1976) cita a coincidência de, em um curto espaço de tempo, depararmo-nos com situações ligadas a um mesmo número ou nome de pessoa, o que pode vir a adquirir um ar secreto de sina ou maldição. Aqui, além de reafirmar a vinculação do inquietante retorno do igual a elementos da psicologia infantil, Freud (1919/1976) expõe a sua hipótese de que a vida psíquica é essencialmente pulsional, ou seja, dominada por um excesso de sentido,

Para Laplanche e Pontalis (1987/1992), este se qualifica enquanto um "Complexo centrado na fantasia de castração, que proporciona uma resposta ao enigma que a diferença anatômica dos sexos (presença ou ausência de pênis) coloca para a criança. Essa diferença é atribuída à amputação do pênis na menina. A estrutura e os efeitos do complexo de castração são diferentes no menino e na menina. O menino teme a castração como realização de uma ameaça paterna em resposta às suas atividades sexuais, surgindo daí uma intensa angústia de castração. Na menina, a ausência do pênis é sentida como um dano sofrido que ela procura negar, compensar ou reparar. $\mathrm{O}$ complexo de castração está em estreita relação com o complexo de Édipo e, mais especialmente, com a função interditória e normativa" (p. 73). 
intimamente vinculado, por sua vez, a um impulso de repetição que não pode ser simbolizado pela via da linguagem e que por isso teima em reaparecer sob a inquietante forma do sinistro.

Freud (1919/1976) escolhe ainda algumas outras situações para sustentar a sua argumentação. Dentre elas, o confronto com a morte e seus conteúdos, o encontro com o próprio homem enquanto outro potencialmente ameaçador e - importante - o caráter unhemlich provocado por qualquer sensação de um fím da distinção entre imaginação e realidade. Isto significa que há uma (con)fusão entre o eu e o mundo para além do campo da linguagem representacional, quando: “... aparece diante de nós como real algo que havíamos tomado por fantástico, quando um símbolo assume a plena operação e significado do simbolizado ..." (Freud, 1919/1976, p. 244; tradução nossa). Segundo o mesmo Freud (1919/1976), poderíamos perceber aí a presença de uma supervalorização da realidade psíquica em contraponto à realidade material, associada, por seu turno, à chamada onipotência dos pensamentos.

Esses são, em termos gerais, os argumentos utilizados por Freud (1919/1976) em defesa da aplicabilidade da sua hipótese, a qual, como vimos ao longo desta exposição, associa a sensação unheimlich ao retorno de um conteúdo familiar anteriormente reprimido. Guardemos conosco esta perspectiva e com ela passemos agora ao segundo momento do presente estudo, voltado para uma tentativa de aproximação entre os universos da psicanálise e aquele outro, próprio à experiência cinematográfica - no presente caso, representada pelo filme Encontros $e$ Desencontros. Tal aproximação, porém, de maneira alguma se pretende conclusiva, engessando ou encaixando forçosamente as propriedades do filme nos limites impostos por instrumentos de natureza teórica pré-concebidos. Trata-se, sim, de um exercício do pensar analítico atento quanto a preservar uma importante qualidade do sentido: aquela de movimento.

\section{PERDIDOS NO TRASLADO: ENCONTROS E DESENCONTROS COM O OUTRO DE SI}

Vencedor do Globo de Ouro e do Oscar de melhor roteiro de 2004, Encontros e Desencontros conta com a direção de Sofia Coppola, uma destacada fotografia e ótimas atuações de Bill Murray e Scarlett Johanson para trazer ao público um tempero delicado e, ao mesmo tempo, muito bem distribuído entre o trágico e o cômico. Trata-se, na verdade, de um filme que instiga por nos convidar a um constante jogo de movimento e indefinição, de transição entre espaços, de impossibilidade de tradução - seja do si mesmo, seja do outro.

Com efeito, o próprio título original, Lost in Translation - ou, traduzido literalmente, Perdido(s) na Tradução - já nos fornece uma ideia de incompreensão e, ao mesmo tempo, de traslado, de um movimento rumo a algo ou a outro lugar. De nós para com os outros? De nós para conosco? Ou, ainda, de nós para nós mesmos por intermédio de estranhos? Dito de outra maneira, o filme traz um jogo de lugares, de passagens entre o si mesmo e o outro, onde Sofia Coppola exerce com maestria a arte de exaltar as ambiguidades do olhar.

Nesses termos, temos aí um filme sobre um malestar específico, sobre uma angústia ligada ao vazio, a um irrepresentável que, curiosamente, pode vir a adquirir alguns contornos pelo contato com um estranho - no caso, um conterrâneo em uma terra de estrangeiros, como é o caso da inusitada relação entre Charlotte e Bob, personagens principais da trama que, por diferentes razões, encontram-se em visita a Tóquio, no Japão. Passemos a eles.

Charlotte é uma jovem recém-casada e recémformada. Curiosamente, uma filósofa incapaz de representar a si mesma após frustrações nos campos da fotografia e da escrita. Não se reconhece, tampouco é reconhecida pelo olhar do marido - que, vale a pena ressaltar, é um fotógrafo (um profissional do olhar) -, um estranho com o qual trocou alianças e, em algumas cenas, divide um quarto de hotel. Interessante notar que este irrepresentável de si que o filme nos traz escapa ou excede àquele terreno próprio à razão instrumental. Neste sentido, a figura de Charlotte, em sua qualidade de filósofa graduada por uma das mais importantes faculdades dos Estados Unidos (Yale), se torna muito representativa, já que a personagem não dá conta de representar a si mesma em termos de desejo, de presente, de futuro ou de relações objetais.

Alguns reflexos dessa busca de Charlotte por si mesma podem ser encontrados nas cenas em que telefonema para uma amiga, quando se maquia em frente ao espelho, no enfeite particularizado com o qual decora o seu impessoal quarto de hotel e na observação de algumas fotos antigas com John (seu marido), além da audição de um áudio-book com o sugestivo título A Soul's Search (A Procura de uma Alma - que bem pode ser a sua própria ou a alma "gêmea" de outrem). Neste sentido, temos aí mais um dos jogos propostos pelo filme, jogo esse relacionado à tentativa de uma reconstituição de si por parte de Charlotte - enfim, reconstituição da sua história, das suas escolhas, da sua beleza, dos seus gostos e modos específicos de ver ou estetizar a própria existência.

Já Bob se apresenta como um homem de meiaidade, ator de considerável sucesso em filmes da 
década de 70, mas que hoje vem a Tóquio para, com a sua imagem um tanto desgastada pelo tempo, promover um Whisky por vantajosa soma em dinheiro. Assim como Charlotte, também sugere uma imagem de decadência e despersonalização revelada, por exemplo, no pastiche que faz de outras famosas estrelas do Ocidente, como Frank Sinatra ou Roger Moore, quando da sessão de fotos para a propaganda do referido Whisky. Além disto, Bob apresenta uma relação de absoluta estranheza com a esposa e filhos que ficaram na América. Com efeito, diante da solidão e das inquietações com a própria vida e relações familiares, Bob se refugia na bebida e na companhia de estranhos em um bar de hotel.

Pois bem, o primeiro encontro entre Bob e Charlotte ocorre com uma furtiva troca de olhares em um elevador repleto de orientais; ou seja, são próximos que se encontram em meio a outros, à diferença, já que, se ambos estivessem nos Estados Unidos, provavelmente não teriam notado um ao outro de maneira tão intensa. O segundo encontro se dá no bar do hotel. Desta feita, com olhares intermediados por sorrisos e a oferta, feita por Charlotte, de um drink para Bob. O terceiro encontro se dá novamente no bar do hotel, agora com uma conversa particular. Aqui, no diálogo com a estranheza do outro, somos remetidos com Bob e Charlotte à própria estranheza e ao silêncio do indizível do si mesmo.

De fato, as vivências dos personagens principais de Encontros e Desencontros nos apresentam imagens de desfiliação, de desnaturalização e, com isto, da busca pelo olhar tradutor de um outro; e é a partir da resposta deste último que advém a abertura rumo ao novo, à possibilidade de diferentes olhares dos personagens sobre a cidade-alteridade e sobre as suas próprias vidas.

Nesses termos, Bob e Charlotte saem para se divertir com alguns conhecidos dela na noite japonesa e as cenas seguintes sugerem a possibilidade de se sentir confortável entre estranhos. Afinal, durante o encontro, uma das músicas cantadas por Bob em um karaokê é More Than This, um sucesso do início dos anos 80 que traz consigo o seguinte refrão: "Nada além disso. Você sabe que não há nada além disso. Diga-me uma só coisa além disso". Há aqui a ideia de um encontro, de uma - mesmo que momentânea sensação de paz ou plenitude maior do que a retratada pelo filme na relação de Bob com a sua própria esposa e filhos que ficaram na América.

O filme apresenta ainda vários outros encontros entre Bob e Charlotte, seja em restaurantes, seja em um hospital. De qualquer forma, algo que vale a pena notar é que, embora tenham idades distintas e tragam diferentes experiências de vida, ambos apresentam pelo menos duas grandes coisas em comum: certa insatisfação quanto ao presente e a angústia em relação ao futuro. Na verdade, é a própria temática do duplo que aparece presente na relação entre os dois personagens, ao mesmo tempo tão diferentes e tão próximos a ponto de quase se confundirem.

As figuras de Bob e Charlotte expõem mesmo tanto o contraste quanto a interação entre o velho e o novo. Com efeito, torna-se bem exemplar o diálogo que travam deitados em uma cama de hotel, o qual gira em torno do sentido das coisas: "estará ele no futuro?", Charlotte parece perguntar. "Estará em um passado jovial e esperanço, mas agora distante?" (aquele próprio a Bob e que Charlotte agora representa).

Não obstante, uma inquietação permanece, um não definido, um não traduzido, um persistente bordejar entre o contato com o outro e o mergulho nas próprias incertezas. Cabe aqui a pergunta: trata-se de um olhar sobre si mesmo para tentar se reconstituir ou para se des-conhecer? Este é mais um dos reflexos do jogo entre luz e sombra, entre familiaridade e estranheza, que permeia todo o filme e marca também as variadas cenas dos personagens de Bob e Charlotte em separado.

De fato, temos aqui a ideia de vidas paralelas, de distintas motivações e buscas de sentido para as próprias histórias de vida; ao mesmo tempo, porém, são destinos que se tocam e contracenam, encontrando-se, ao que parece, consigo mesmos um através do outro nas suas (des)semelhanças. Neste sentido, torna-se também digna de nota a inquietação imposta ao expectador pelo filme em termos da indefinição da relação entre seus dois personagens principais. Flertarão? Consumarão um encontro apaixonado ou irão se manter (e a nós também) suspensos e desencontrados?

Outra dimensão inquietante - pois marcada pela indefinição, pela não demarcação de fronteiras claramente desenhadas - também presente no filme é a do lusco-fusco de sono (sonho) e vigília que marca as trajetórias de Bob e Charlotte. Quando se está dormindo? Quando se está acordado? O que é - ou parece - real e o que é imaginação? Será a vida em si apenas um shakesperiano sonhar acordado? Note-se que esta mesma ideia aparece presente em variadas cenas, onde se destacam jovens japoneses se divertindo em jogos eletrônicos que, em sua virtualidade, simulam a vida real. Nelas vemos tambores ligados a fios elétricos e a uma máquina de fliperama e também uma guitarra que, ao invés de cordas, conta com sensores também conectados a uma máquina de jogo.

$\mathrm{Na}$ verdade, quando apresentada no filme, a própria geografia urbana aponta uma terra que desconcerta pelo seu caráter estranhamente familiar, o 
qual não parece se situar nem aqui nem acolá; ou seja, temos um Oriente enquanto ambiente étnico e cultural distinto (por vezes inóspito), mas que também aparece como portador de duplos na forma de pastiches que remetem ao american way of life. Mais ainda: há inúmeras tomadas de estradas, ruas, pontes, carros (incluindo-se aí repetidas cenas no interior de táxis), trens e metrôs que denotam uma ideia quase surreal de eterna passagem ou movimento, de uma transição de ordem física que acaba por se remeter ao terreno psíquico.

Aliás, o próprio retorno de Bob e Charlotte acaba sempre por se dar para um lar que não é exatamente um lar, já que é um hotel (projetado para ser impessoal), cujos quartos por eles ocupados podem ser pensados como metáforas do próprio sujeito do inconsciente. Afinal, trata-se de espaços do próximo, do familiar e, ao mesmo tempo, do distante - e, por isso mesmo - inquietante outro de si.

Com efeito, através dos vidros destes mesmos quartos de hotel somos levados a contemplar uma cidade que, vista de cima, sugere algo aparentemente familiar (mesmo que - ou, talvez, precisamente - pela sua cinza impessoalidade de concreto). Ao mesmo tempo, quando da descida dos personagens em direção às povoadas ruas de Tóquio, as imagens locais evidenciam um caldeirão de diferenças culturais (ou nem tanto?). Trata-se, portanto, de mais um dos jogos entre proximidade e distância propostos pelo filme, o qual, como dissemos há pouco, utiliza diversos contrapontos de tipo étnico, geográfico e cultural para pôr em relevo a alteridade psíquica, a inquietante estranheza que se esconde por detrás da reconfortante (mas também ilusória) consciência de nós mesmos.

Nesse mesmo sentido, outro importante aspecto a ser levado em conta ao longo da trama diz respeito ao valor conferido por esta ao idioma, à linguagem, pois Encontros e Desencontros nos coloca frente a frente com pessoas que insistem em dizer a outras o que fazer em uma língua desconhecida - isto é, que não provoca ou traz sentido. Exemplos podem ser vistos em cenas de Bob com alguns fotógrafos e publicitários japoneses, bem como nos hilários diálogos de surdos promovidos pelo mesmo Bob e por Charlotte junto a um paciente e a um médico quando da visita que fazem a um hospital.

Ainda no que se refere à importância da linguagem no filme de Sofia Coppola, vale notar que em meio a tantos des(encontros) a frase "eu te amo" aparece como uma espécie de muleta diante do desconforto, da angústia do irrepresentável tanto na relação de Bob e sua esposa Lydia quanto naquela de Charlotte e seu marido John. Interessante notar também que, embora recorrentemente convocado, este mesmo "eu te amo" jamais é correspondido nos diálogos em que aparece. Em outros termos, por mais que seja falada em inglês - e não em uma língua desconhecida dos personagens -, tal expressão parece mesmo não ser bem compreendida nem por quem fala nem por quem ouve (ainda que se trate aqui de personagens que dominam um mesmo idioma), mais funcionando para aplacar o estranho de si mesmo do que visando de fato um outro ao qual a frase é dirigida.

Em tal entrechoque entre o eu e o outro se torna possível perceber o peso do cotidiano da vida a dois e, nela, o que por vezes pode soar demasiado medíocre ou superficial, levando os personagens a reflexões do tipo: "Ainda terá meu/minha companheiro/a alguma importância?"; "Serei eu mesmo/a ainda importante?" - tudo isto acompanhado da difícil constatação de que tal dúvida também atormenta o outro.

Por outro lado, a cúmplice relação de Bob e Charlotte não precisa desse apoio, dessa reafirmação, que acaba por se tornar vazia, pois seus encontros se sustentam com um olhar e um cuidado que não necessariamente vêm reafirmados em palavras. A título de exemplo podemos citar a preocupação de Bob em levar Charlotte ao hospital e, na saída, a sua delicadeza em presenteá-la com uma grande e sugestiva coruja de pelúcia. Tal coruja, aliás - além de representar as inúmeras horas insones que partilham -, vincula-os em termos simbólicos enquanto representante desta mesma vigília em relação ao outro da qual acabamos de falar.

Já nos encaminhando para as últimas cenas, temos uma despedida no hall do hotel que acabará por não se revelar a derradeira. Afinal, enquanto espectadores, ainda seremos conduzidos a um novo encontro - desta feita, na rua, ditado pelo acaso da visão que tem Bob, dentro de um táxi a caminho do aeroporto, da figura de Charlotte cruzando uma movimentada rua de Tóquio. Bob a busca em meio aos outros, em meio a uma massa aparentemente homogênea de pessoas. Seguem-se um forte abraço, um afago e palavras sussurradas ao ouvido - pronunciadas por Bob bem baixinho, muito provavelmente para não poderem mesmo ser traduzidas ou legendadas, isto é, para que não as possamos decifrar em sua totalidade. De fato, podemos apenas conjecturar, e isto graças às feições dos personagens, que nos apresentam sorrisos um tanto inquietos - mas, ao que parece, também um tanto libertos.

A câmera produz então uma expressiva tomada à distância e, junto com ela, a visão de Bob e Charlotte ali, ao fundo, parados e abraçados em meio ao fluxo da vida, em meio à multidão aparentemente uniforme que vem e vai. De repente, um rápido beijo, um adeus e um último e demorado olhar até darem as costas um ao outro, desaparecendo em sentidos diametralmente 
opostos. Parece haver entre ambos um querer ir (ou, no caso, voltar) e, ao mesmo tempo, um querer ficar. Prazer, sonho e realidade.

Ao final, permanece a realidade - agora temperada, talvez, com a presença (ou o retorno) deste outro de nós mesmos com o qual tão pouco costumamos nos familiarizar. De volta ao táxi, deparamo-nos com um close de Bob; em seguida, com uma câmera que se desloca rumo aos carros, ruas, torres, prédios e túneis de uma cidade que se esvai em sinais luminosos e letreiros de néon. Partimos, então, rumo a novos traslados a serem traduzidos. Ou não.

\section{CONSIDERAÇÕES FINAIS}

As leituras que fizemos do texto de Freud (1919/1976) e do filme Encontros e Desencontros revelam a presença do oblíquo em movimento em termos de subjetividade. Entramos, assim, no terreno da ética, mas não de uma ética qualquer, e sim daquela que, ao evitar reduzir o outro a códigos semânticos predefinidos, admite a íntima relação que se estabelece entre conhecimento e alteridade. Aqui o estranho e o fragmentário aparecem como lugares ao mesmo tempo do assustador e de uma possível construção criativa, de um meio-termo entre a experiência do vazio e a produção de sentido. Com feito, torna-se interessante notar que a consciência da mobilidade deste sentido relacional (portanto, não transcendente) não significa a desrazão ou o fim do logos, mas, ao contrário, a ampliação das potencialidades deste último.

Tal ideia pode ser avaliada com mais propriedade se levarmos em conta que em ambos os casos - ou seja, no trabalho de Freud (1919/1976) e no filme Encontros e Desencontros - faz-se presente a simultaneidade de duas curiosas afirmações: a primeira delas, relativa a um mal-estar, à angustiante presença do inominável na sombra do aparentemente familiar; e a segunda, inseparável da anterior, afirma que seria possível entrar em contato com ele por intermédio de um outro, de um estrangeiro com o seu olhar mais ou menos referente. É o entrechoque entre o estranho mais íntimo e o íntimo mais estranho, relativo a um não elaborado que inquieta por estar vinculado ao que temos de mais íntimo: o processo primário, o registro do inconsciente, algo pouco ou rudimentarmente representável que, por isso mesmo, insistimos em repetir.

Quantas implicações possíveis deste encontro com o outro, não? Principalmente se nos remetem ao outro de nós mesmos. Afinal, temos aí uma experiência permeada pela introjeção e pela projeção, a qual pode ser percebida pelos sentidos, mas não necessariamente enquadrada pela consciência, clivando-nos e deslocando sensações e julgamentos para além dos seguros limites de uma suposta - mas, como vemos, enganosa - coerência. Eis, portanto, o abismo imposto pela alteridade, revelando um inquietante que põe em cheque a nossa própria ilusão de autonomia. Então, já que não nos livramos de tal desconforto, resta fazer dele algo criativo.

Pois bem, é precisamente nesse sentido que os delicados e surpreendentes Encontros e Desencontros de Sofia Coppola parecem retratar nas vivas cores do cinema atual o tipo de lógica e, junto com ela, as potencialidades do saber analítico em seu trato com o inconsciente. Qual o seu traço mais característico e, ao mesmo tempo, mais radical, senão a destruição do centro (a origem) de qualquer subjetividade, problematizando com isso a própria noção de experiência? Aqui, muito embora o não familiar ainda apareça vinculado a uma desconfortável angústia, descortina-se uma diferente expressão: aquela de potência construtiva em termos de abertura de sentido. Com efeito, o espaço do fragmento aparece como espaço para o novo, para um, por vezes, desconcertante movimento de ideias que se estende para além da simples descoberta ou de qualquer apreensão teórica do tipo formalista.

Neste contexto, a tradução deve mesmo ser compreendida como traslado ou demanda de significado, ao invés da qualidade de um algo já existente a ser decifrado, que, nesta condição, simplesmente aguardaria confirmação. Destarte, a ênfase aqui não recai nem sobre um a priori nem sobre um a posteriori do sentido, mas no próprio movimento do fazer sentido, situando-se a palavra em uma fala que brote da escuta do ser como abismo, isto é, a partir de uma aspiração pelo conhecimento que se estabelece precisamente na renúncia tanto ao pressuposto da verdade como correspondência quanto a qualquer ideal de representação plena.

Em última análise, trata-se mesmo da afirmação de um campo do possível que justifique renovadas aproximações entre inconsciente e cultura - com a ressalva, é claro, de que esta última deve ser pensada enquanto potência criativa que, resistindo à tentação de encarcerar o desejo, evite assim transformá-lo em uma espécie de mandamento.

\section{REFERÊNCIAS}

Cesarotto, O. (1996). No olho do outro. São Paulo: Iluminuras.

Chnaiderman, M. (1997). Rasgando a fantasia para outras tantas mil e uma noites: sobre o texto de Freud 'O estranhamente familiar'. In S. L. Alonso \& A. M. Leal (Orgs.), Freud: um ciclo de leituras (pp. 219-233). São Paulo: Escuta/FAPESP. 
Figueiredo, L. C. (1999). Palavras cruzadas entre Freud e Ferenczi. São Paulo: Escuta.

Freud, S. (1976). Lo ominoso. In J. Etcheverry (Ed. e Trad.), Obras completas (Vol. 17, pp. 215-251). Buenos Aires: Amorrortu. (Original publicado em 1919).

Freud, S. (1976). Más allá del principio de placer. In J. Etcheverry (Ed. e Trad.), Obras completas (Vol. 18, pp. 1-62). Buenos Aires: Amorrortu. (Original publicado em 1920).

Hoffmann, E. T. A. (1983). Los elixires del diablo. (C. Bravo-Villasante, Trad.). Madrid: Ed. Mascarón. (Original publicado em 1816).

Hoffmann, E. T. A. (1993). O homem da areia. (C. Cavalcanti, Trad.). In Histórias fantásticas (pp. 113146). Rio de Janeiro: Imago. (Original publicado em 1817).

Kaplan, E. A. (2000). Freud, cinema e cultura. (V. Ribeiro, Trad.). In M. S. Roth (Org.), Freud: conflito e cultura (pp. 137-148). Rio de Janeiro: Jorge Zahar.
Kofman, S. (1973). Le double e(s)t le diable: l'inquiétante étrangeté de L'homme au sable (Der Sandmann). In Quatre romans analytiques (pp. 135-181). Paris: Éditions Galilée.

Kristeva, J. (1994). Estrangeiros para nós mesmos. (M. Gomes, Trad.). Rio de Janeiro: Rocco.

Laplanche, J., \& Pontalis, J. B. (1987/1992). Vocabulário da psicanálise (P. Tamen, Trad.). São Paulo: Martins Fontes.

Rivera, T. (2008). Cinema, imagem e psicanálise. Rio de Janeiro: Jorge Zahar.
Endereço para correspondência:

Mauricio Rodrigues Souza. Faculdade de Psicologia da Universidade Federal do Pará. Rua Augusto Corrêa, 01, Bairro do Guamá, CEP 66075-110, Belém-PA. E-mail: mrsouza@ufpa.br. 